\section{Military Technical College \\ Kobry El-Kobbah, Cairo, Egypt}

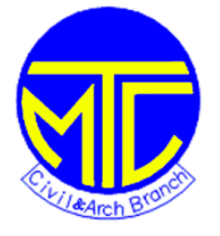

\section{$10^{\text {th }}$ International Conference on Civil and Architecture Engineering ICCAE-10-2014}

\title{
Effect of Geofoam on Slope Stabilizing
}

\author{
M.S.EL-Kady ${ }^{1}$, E.F.Badrawi ${ }^{2}$ \\ ${ }^{1}$ Lecturer, Structural Engineering Department, Faculty of Engineering, Zagazig University, Egypt. \\ ${ }^{2}$ Lecturer, Structural Engineering Department, Faculty of Engineering, Zagazig University, Egypt.
}

\section{1- Abstract}

Slope stability is one of the most important problems in geotechnical engineering because failure could cause catastrophic environmental and human disaster, in addition to large economical losses due to such failure. There are different techniques used for stabilizing slopes and to increase the slope safety factor, such as rubble, slope stabilizing piles. Slopes could fail under different types of external loads, changing in the surrounding environmental conditions such as the water table and many other reasons could cause such failures in the slope. The simplest solution to handle with slope failures is to avoid the failed zones and choose safer locations to move the projects which are decided to be constructed nearby the failed slopes. But this solution could not be applied in most cases with the increase of populations and the construction activities. For this reasons many stabilizing systems were introduced in order to stabilize slopes and to increase the slope safety factors to avoid expected failure. The choice of an adequate stabilizing system should be based on geological and hydrological explorations and a comprehensive site investigation considering the most economical system and materials availability.

The purpose of this paper is to investigate the effect of geofoam on soft clayey slopes which contain weak layers. The analysis of the embankment is performed by the limit equilibrium analysis program (Slide V6.003). The main factors which affect the slopes stabilized with geofoam such as, geofoam width, thickness, and position of the geofoam from the road level are also presented and discussed.

Keywords: Slope Stability, Geofoam, Factor of Safety, Local Failure, Slip Failure.

\section{2-Introduction}

Researchers were concerned in introducing techniques that help in evaluating and modeling slopes, in order to propose the correct judgment of the slope status, and choose the safe and economic technique to stabilize the endangered slopes. The slope must have a stabilizing system 
to increase the safety factor. The slope failures not only cause huge economical losses on the nearby projects, but also could cause human and environmental losses. A main part in overcoming the slope failure problems is to identify the reasons which cause such problem. After defining the cause(s) and gathering the required information about the slope, the geotechnical engineer judgment must intervene to choose the most suitable and economical stabilization system. The factor of safety (F.S.) for slope stability analysis is usually defined as the ratio of the ultimate shear strength divided by the mobilized shear stress at incipient failure. The most common formulation for F.S. assumes the factor of safety to be constant along the slip surface, and is defined with respect to the force or moment equilibrium (Cheng and Lau, 2008):

1- Moment equilibrium: generally used for the analysis of rotational landslides. The F.S is defined with respect of moments.

$$
F . S .=\frac{M_{r}}{M_{d}}
$$

Where $M_{r}$ is the sum of the resisting moments and $M_{d}$ is the sum of the driving moments.

2- Force equilibrium: generally applied to translational or rotational failures composed of planar or polygonal slip surfaces. The factor of safety (F.S.) in such case is defined with respect to force.

$$
F . S .=\frac{F_{r}}{F_{d}}
$$

Where Fr is the sum of the resisting forces and Fd is the sum of the driving forces. Thus, the slope safety factor could be computed from force and/or moment equilibrium equations (Cheng and Lau, 2008). There are many reasons which could cause slope instability. The main reasons which may lead to slope failure are summarized as follows: decreasing of the soil shear strength, existence of problematic soil layers within the slope soil profile such as; peat, collapsible or swelling soils, very soft clay...etc., externally applied high loads on the slope, and rapid drawdown of the water level in front of the slope, while the embankment slope itself is still fully saturated.

The different methods used for stabilizing slopes are divided mainly into three categories; either reducing the driving forces, or increasing the resisting forces, or both. There are large number of stabilizing systems which could be used in stabilizing slopes such as; accelerating the slope drainage rate which will consequently increase the soil shear strength, reducing the sliding mass weight by removing the upper part of the slope or the unstable part if possible depending on the location of this part, using light weight fill materials in slope construction, reducing the slope inclination angle, using retaining systems to support the slope, in addition to reinforcing the slope with piles (vertically), geosynthetics and geogrids (horizontally), nails (inclined)...etc. Other stabilizing techniques are also possible such as dynamic compaction, jet grouting, slope vegetation, and chemical treatment for the slope to increase the shear strength parameters of the soil. Chemical treatment includes using lime or a mix of lime and cement columns and different in-situ soil mixing techniques. Choosing the suitable system which to be used in stabilizing a failed (or expected to fail) slope should be based mainly on identifying the main causes of slope failure, the expected circumstances which will affect the slope in the future, and the best 
economical solution.

\section{3-Slope Geometry and Description}

The erosion or failure in slopes poses a great danger to nearby and surrounding communities. Such slope failure will cause great losses in life and property, and thus should be prevented by any means. Thus, safety of such slopes is a major concern and should always be satisfied in working and extreme loading conditions.

In this research the slope geometry, loading, and geofoam material are numerically simulated using the finite element technique. In addition, the proposed stabilizing system is employed, presented, and analyzed.

The general configurations of the canal's slope are presented in Figure (1). The dimensions presented in the canal cross section, as shown in Figure (1), is based on data from several studies made on this slope starting with a general planning study performed by the Ministry of Irrigation, Egypt along with other studies like the one that performed by Al-Ashaal et al. (1998).

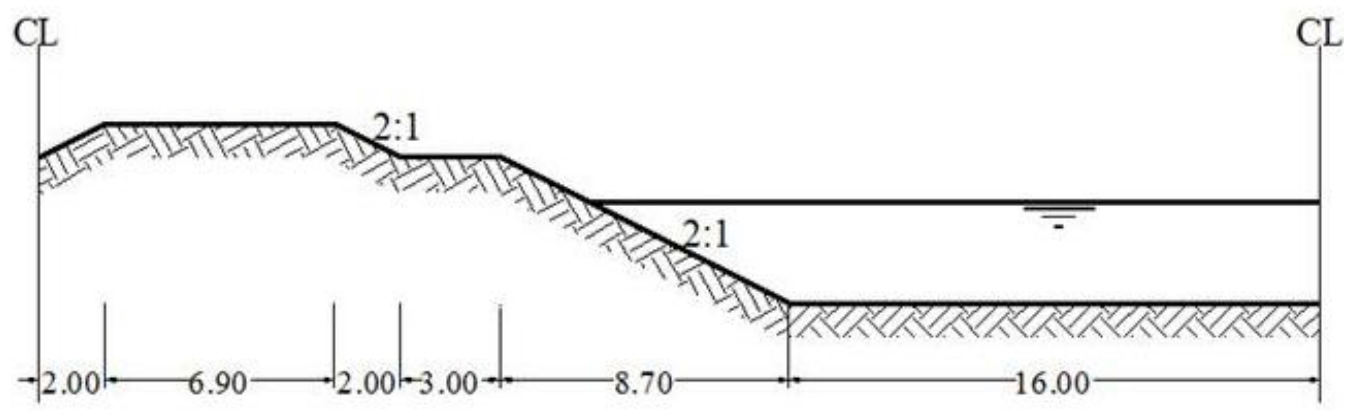

Figure (1): Schematic Diagram of Canal Cross Section.

The project of stabilizing and developing case of study of the Al-Salam canal contains two extensive monitoring zones from $8.800 \mathrm{~km}$ to $8.850 \mathrm{~km}$ and from $7.700 \mathrm{~km}$ to $7.750 \mathrm{~km}$. These zones are mainly chosen due to the presence of the peat layer, as assured from the boreholes performed along the whole embankment length. 


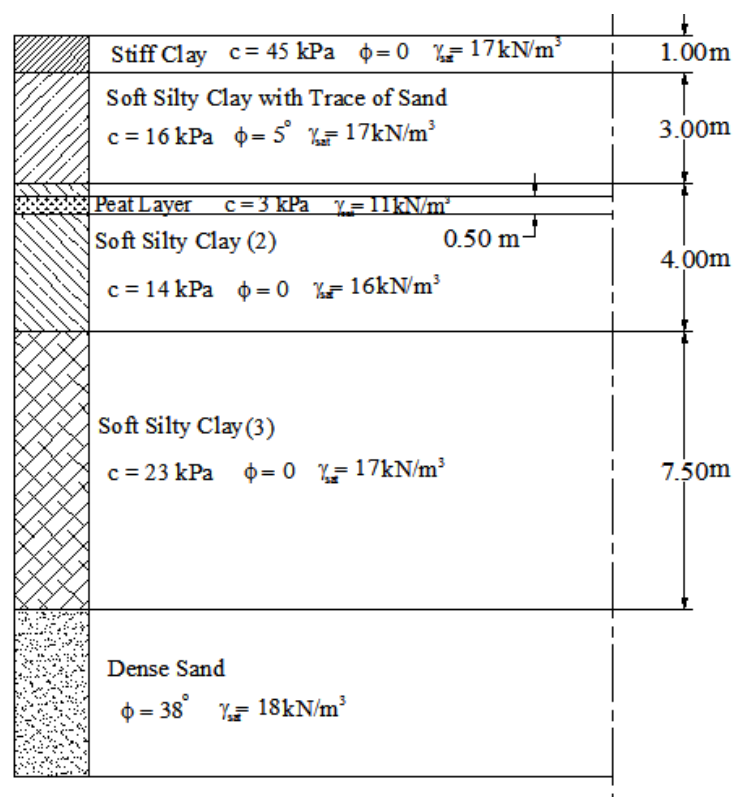

\section{4-Material Properties}

Figure (2): The Slope Soil Stratification.

Geofoam mechanical properties such compressive strength, elastic modulus, possion's ratio, shear strength, flexural strength, stiffness, creep behavior and other mechanical properties depend on the Geofoam unit weight. It should be noted that the manufacturing cost of the Geofoam increases with the increase of the density. For practical civil applications, geofoam densities range between 11 and $30 \mathrm{~kg} / \mathrm{m}^{3}$ (Van Dorp, 1988). Geofoam densities are categorized by ASTM C 578-04 to 5 types, 12, 15, 18, 22, $29 \mathrm{~kg} / \mathrm{m}^{3}$. The geofoam density used in the research is $20 \mathrm{~kg} / \mathrm{m}^{3}$. Higher values of geofoam densities are not used to minimize the actual cost. The properties of geofoam having a unit weight of $20 \mathrm{~kg} / \mathrm{m}^{3}$ manufactured in Egypt listed in Table (1).

Table (1): Geofoam Block Properties.

\begin{tabular}{|c|c|}
\hline Geofoam properties & Value \\
\hline Unconfined compressive strength at $10 \%$ strain, $(\mathrm{kPa})$ & 94.5 \\
\hline Initial elastic modules, $(\mathrm{kPa})$ & 3549 \\
\hline Poisson's ratio & 0.01 \\
\hline Angle of friction, $\left(^{\mathrm{o}}\right)$ & 15.87 \\
\hline Cohesion, $(\mathrm{kPa})$ & 27.07 \\
\hline Flexural Strength, $(\mathrm{kPa})$ & 245.4 \\
\hline
\end{tabular}


Proceedings of the $\mathbf{1 0}^{\text {th }}$ ICCAE-10 Conference, 27-29 May, 2014

\begin{tabular}{|c|c|}
\hline Flexural Strain, (\%) & 6.3 \\
\hline The coefficient of compressibility, $\left(\mathrm{MPa}^{-1}\right)$ & 0.479 \\
\hline Compression Index & 56.5 \\
\hline Recompression Index & 2.51 \\
\hline Water absorption after 28 days, (\%) & $2.45 \%$ \\
\hline
\end{tabular}




\section{5-The Finite Element Program Description}

In the last decades, there were huge jumps in the field of computer science either in the software or in the hardware. The finite element analysis has proved to be a powerful tool in analyzing a wide range of geotechnical problems. Different algorithms were created and adapted in order to optimize the finite element solutions and reduce the time required for problem analysis. Applying the finite element method in geotechnical engineering allows for modeling many applications such as slope stability analysis, earth dams, tunnels, along with many dynamic applications. This powerful and flexible technique has the ability of simulating varies soil applications and conditions. In the current analysis, the different factors affecting the slope stability should be taken into consideration to ensure the accuracy of the slope analysis results and specifying the important parameters that affect slopes stabilized with piles such as; the soil shear strength parameters, the presence and the position of the peat layer within the slope, the slope inclination angle, the slope height, the external loads value, the soil Young's modulus.

The quality of the FEM is directly dependent on the ability of the selected constitutive model to realistically simulate the nonlinear behavior of the soil within the slope, Abramson et al. (2002). The finite element program used in the slope analysis software is (Slide V6.003). It is a 2dimensional elasto-plastic finite element program for calculating stresses and displacements around underground openings, and can be used to solve a wide range of slope stability and civil engineering problems. There are two analysis types in the (Slide V6.003); Plane-Strain and Axisymmetric analyses. Most cases will be simulated using Plane-Strain conditions. The Axisymmetric option allows analyzing 3-dimensional problems which is rotationally symmetric about an axis. The input is 2-dimensional, but because of the rotational symmetry, but in fact it is a symmetric 3-dimensional problems revolving about an axis (Slide V6.003). The program supports analysis of elastic and plastic materials but plastic material properties are defined only with isotropic properties. The program allows for simulating the construction sequence process by analyzing the model in stages for each construction step. Problem boundaries, materials properties, support properties, ground water table, loads and other features in the program could also vary in the different stages. The program allows defining soil strength with many strength criteria; Mohr-Coulomb, Hoek-Brown, Generalized Hoek-Brown, Drucker-Prager, Cam-clay, and Modified Cam-Clay.

\section{6-Parametric Study}

This section is concerned in presenting all the parameters used in this research which affect the slope stability, including the geofoam material on the slope safety factor. The soil properties used in the slope analysis is correlated from the soil investigation reports, along with the data presented in Al-Ashaal, (1998). Also, material characteristics are summarized in Tables (2-3). Also, surcharge pressure is applied to simulate a load equivalent to the 70 ton truck, in addition to $0.10 \mathrm{t} / \mathrm{m}^{2}$ to account for the pavement thickness, with a total test pressure of $3.40 \mathrm{t} / \mathrm{m}^{2}$. 
Table (2): The Dependant Soil Properties on the Shear Strength Parameters.

\begin{tabular}{|c|c|c|c|c|c|c|}
\hline Soil Type & $\begin{array}{c}\gamma_{\text {sat }} \\
\left(\mathbf{k N} / \mathbf{m}^{3}\right)\end{array}$ & E (MPa) & $\nu$ & c (kPa) & $\phi\left(^{0}\right)$ & $\phi\left(^{\mathbf{0}}\right)$ \\
\hline Soft Silty Clay (1) & 17 & 1.70 & 0.45 & 16.0 & 5 & 0 \\
\hline Soft Silty Clay (2) & 16 & 1.40 & 0.45 & 14.0 & 0 & 0 \\
\hline Soft Silty Clay (3) & 17 & 2.00 & 0.45 & 23.0 & 0 & 0 \\
\hline Stiff Clay layer & 17 & 5.90 & 0.45 & 45.0 & 0 & 0 \\
\hline Peat layer & 11 & 0.30 & 0.45 & 3.0 & 0 & 0 \\
\hline Dense sand & 18 & 100.0 & 0.30 & 0.0 & 38 & 8 \\
\hline Gravel layer & 19 & 200.0 & 0.30 & 0.0 & 45 & 15 \\
\hline
\end{tabular}

In which:

$\gamma_{\text {sat }}$ : Saturated unit weight;

E: Soil Young's modulus;

$v$ : Poisson's ratio;

c: Soil cohesion;

$\Phi$ : Angle of internal friction; and

$\Psi$ : Dilation angle ( $\phi-30)$.

Table (3): Model Variables used in Parametric Study.

\begin{tabular}{|c|c|c|}
\hline No. & Parameter & Value/Values \\
\hline 1 & Geofoam Width & $3.0-3.5-4.0-4.5-5.0-5.5-6.0-6.5-6.9$ \\
\hline 2 & Geofoam Thickness & $0.0-0.5-1.0-1.5-2.0-2.5-3.0-3.5-4$. \\
\hline 3 & Geofoam Position & $0.0-0.5-1.0-1.5-2.0-2.5$ \\
\hline
\end{tabular}

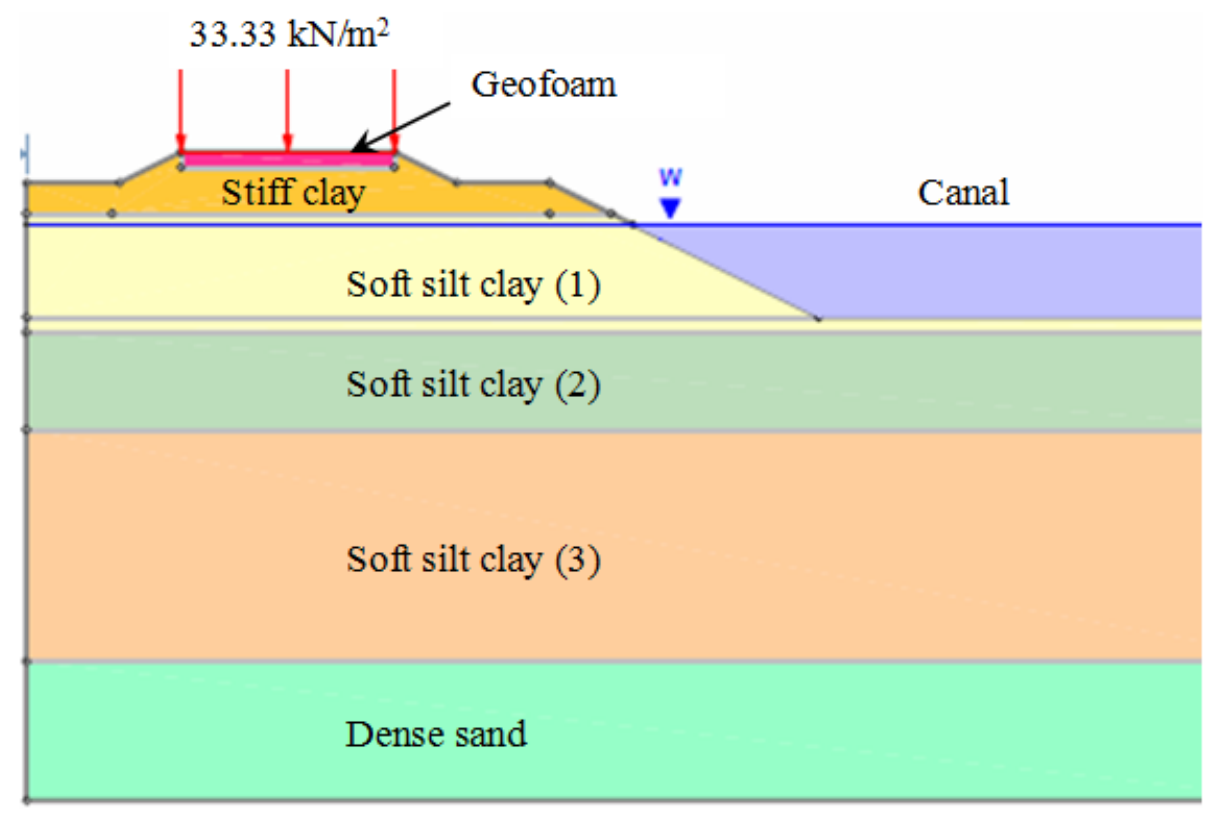

Figure (3): Schematic Diagram of the Embankment Showing Soil Stratification. 


\section{7-Results}

\section{7-1 Effect of Geofoam Thickness on Slope stability}

Figure (4) shows the relation between the geofoam thickness (h) and the safety factor of the stabilized slope (F.S.) for geofoam thickness varies from $0.0 \mathrm{~m}$ to $4.0 \mathrm{~m}$. It is obvious from the figure that increasing the geofoam thickness from $0.0 \mathrm{~m}$ to $1.0 \mathrm{~m}$ resulted in a noticeable increase in the safety factor for loaded and unloaded slopes. For unloaded slope, and due to increasing geofoam thickness from $1.0 \mathrm{~m}$ up to $4.0 \mathrm{~m}$, the safety factor is still constant for about 2.10.

A Consistent increase in the safety factors is noticed as a result of increasing the geofoam thickness from $0.0 \mathrm{~m}$ up to $4.0 \mathrm{~m}$. Figures $(5 \& 6)$ indicates the effect of the geofoam thickness= $0.50 \mathrm{~m}$ on unloaded and loaded slopes, respectively. Geofoam thickness is found to be effective for loaded slopes that because of increasing of the safety factor for about $40 \%$.

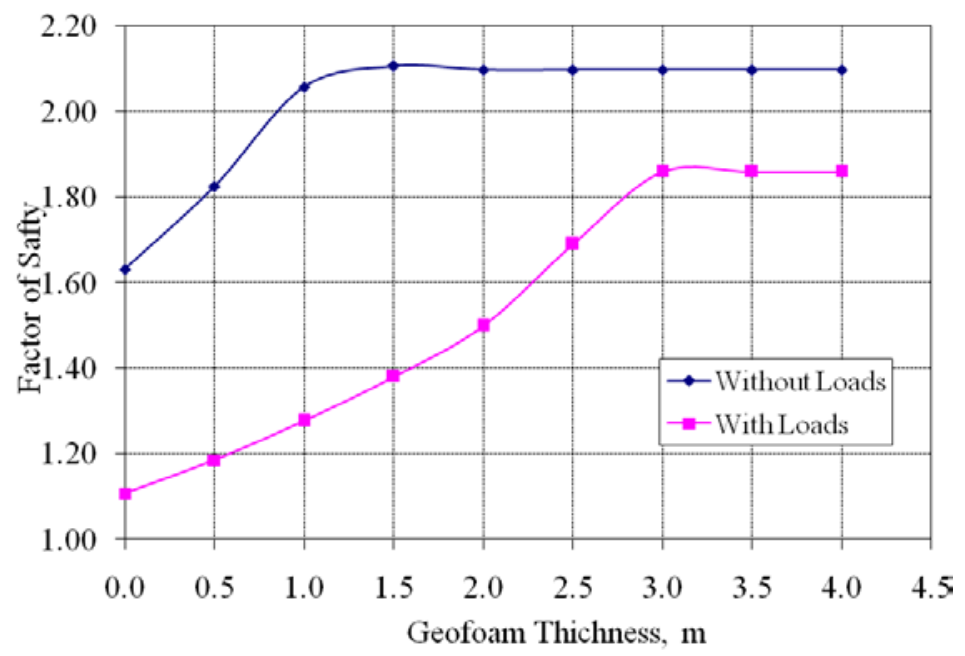

Figure (4): Effect of Geofoam Thickness on the Factor of Safety.

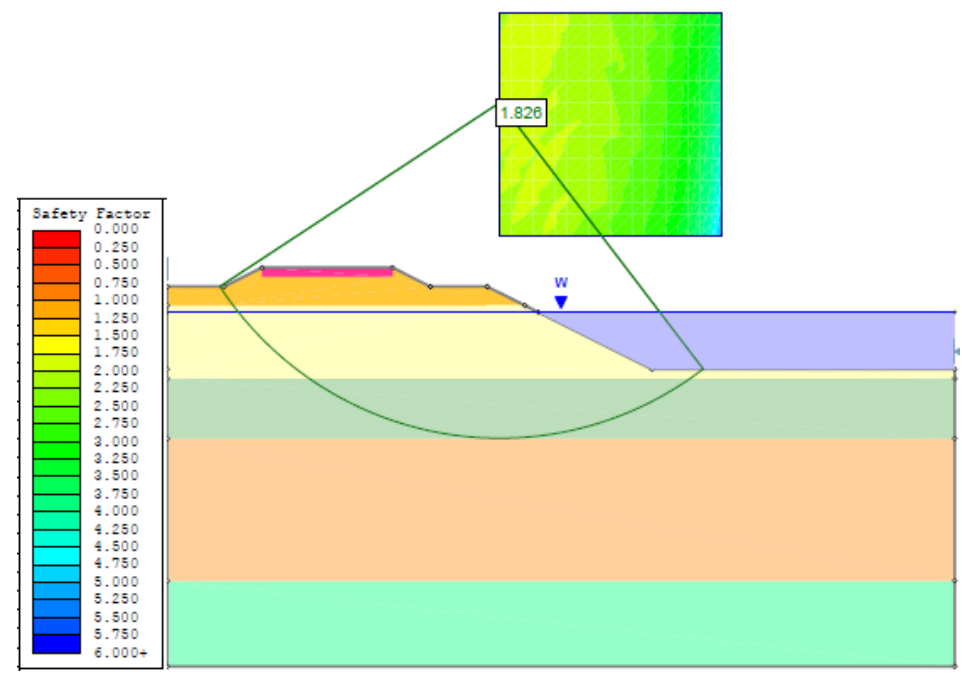

Figure (5): Effect of Geofoam Thickness (0.50m) on (F.S.) for Unloaded Slope. 


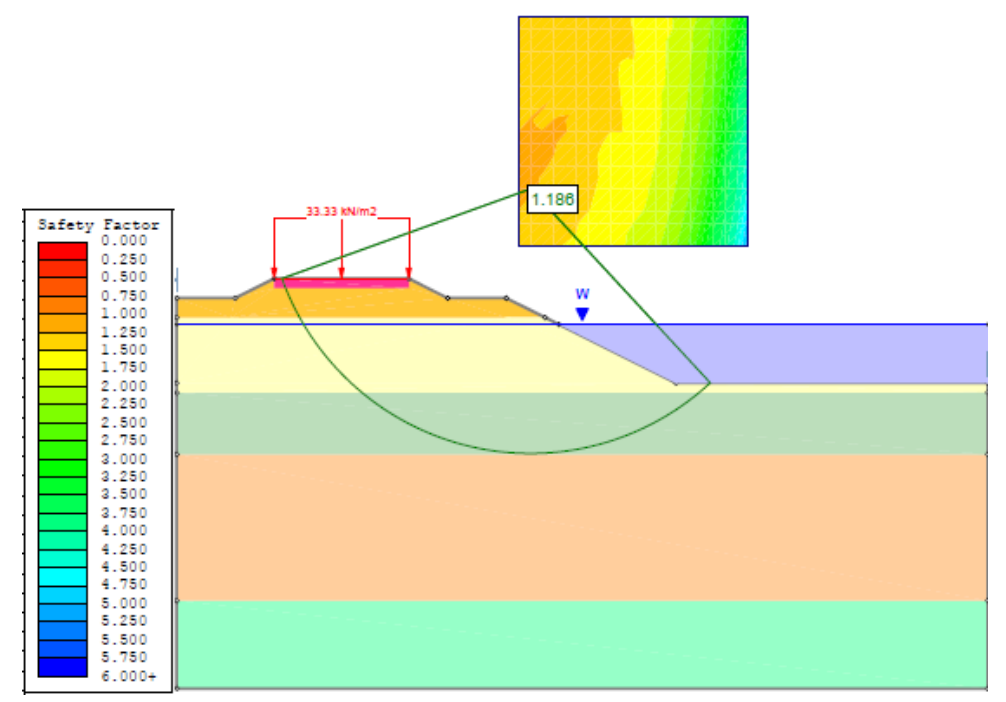

Figure (6): Effect of Geofoam Thickness (0.50m) on (F.S.) for Loaded Slope.

\section{7-2 Effect of Geofoam Position from Road Level on Slope stability}

Figure (7) shows the effect of varying the depth of geofoam layer from the road level. Positions are varies from $0.0 \mathrm{~m}$ (at the road level) up to $2.5 \mathrm{~m}$ from the road level. The geofoam width is constant and equal to embankment width. The studied range of geofoam position $(\mathrm{H})$ from the road level represents a slight increase in the safety factor for unloaded slopes. On the contrary, there is a slight decrease in the safety factor for loaded slopes during different values of geofoam position from the road level.

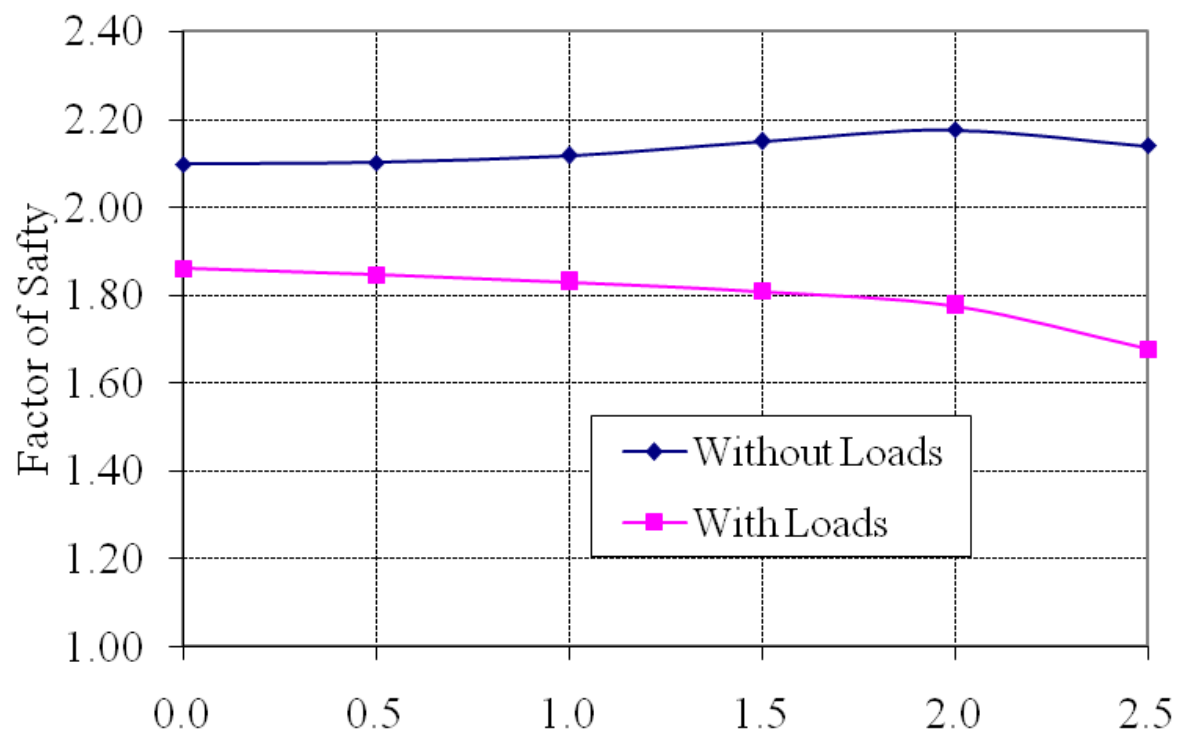

Geofoam Postion From Road Level, m

Figure (7): Effect of Geofoam Position from Road Level on the Factor of Safety. 


\section{7-3 Effect of Geofoam Width on Slope stability}

Figure (8) shows the relation between the geofoam width (B) and safety factors for constant depth of the geofoam layer of $0.50 \mathrm{~m}$ from the embankment level. The relation between the geofoam width and safety factors is directly proportional, as increasing the geofoam width will increase the safety factor. For unloaded slopes, there is a slight increase of the safety factors. The values changed from 1.80 at $\mathrm{B}=3 \mathrm{~m}$ to 2.10 at $\mathrm{B}=6.9 \mathrm{~m}$. On the other hand, a clear increase is noticed for loaded slopes in safety factors. The values changed from 1.35 at $\mathrm{B}=3 \mathrm{~m}$ to 1.84 at $\mathrm{B}$ $=6.9 \mathrm{~m}$.

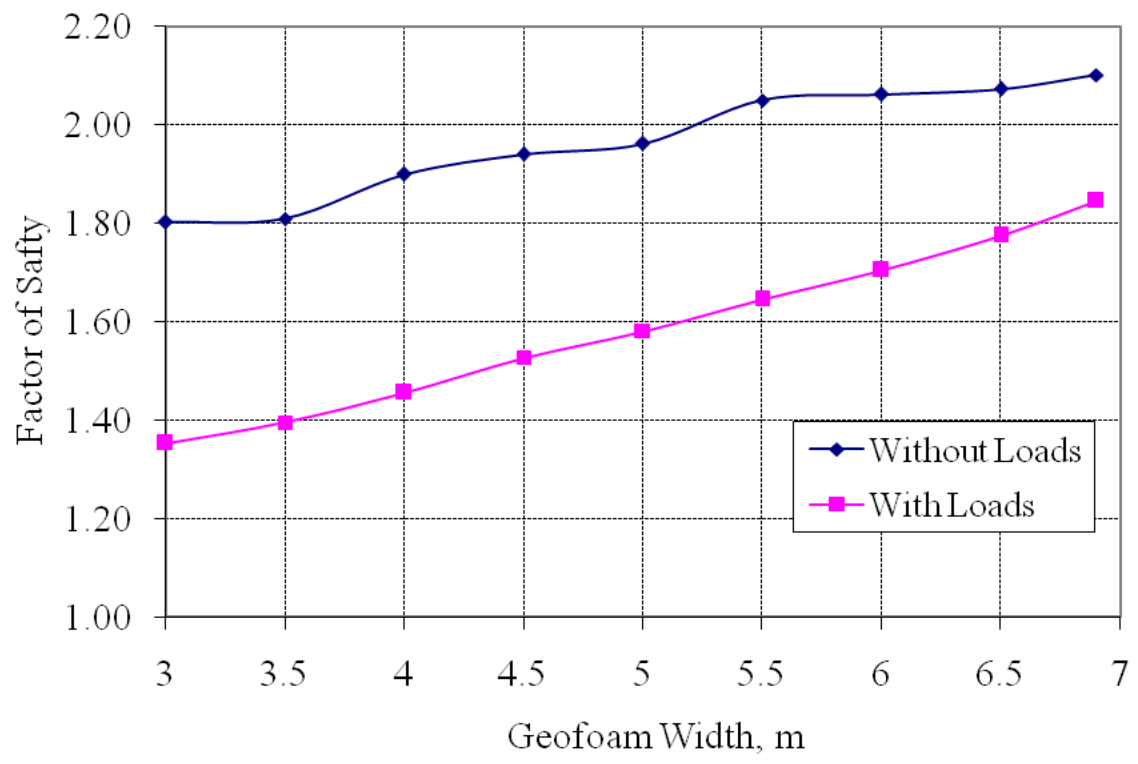

Figure (8): Effect of Geofoam Width on the Factor of Safety.

\section{8-Conclusions}

This paper presents the results of study of the effect of geofoam on the slope stabilization under loaded and unloaded slope embankment. Based on the results of the current research, the following conclusions are drawn:

1- Partial replacement of slope embankment by geofoam is a successful and efficient solution to increase the factor of safety of the slope.

2- Limit equilibrium results showed that using a geofoam thickness equal to the $1.0 \mathrm{~m}$ is effective in increasing the factor of safety in both loaded and unloaded slope. In addition, the increasing of the safety factor of the loaded slope is about $40 \%$. Thus, it is recommended to use geofoam thickness equal to $1.0 \mathrm{~m}$.

3- Results indicated that the position of the geofoam layer from road level is not that effective in reducing the factor of safety. Therefore, a geofoam layer at the road surface with coated by 0.50 $\mathrm{m}$ of sand layer is considered efficient and economic.

4- Results showed that using a geofoam width for case of loaded and unloaded slope is effective in increasing the factor of safety. The increasing of the safety factor of the unloaded and loaded slope are $34 \%$ and $38 \%$ respectively. 


\section{9-References}

[1] Abramson, L.W., Lee, T. S., Sharma, S., and Boyce, G. M., (2002), "Slope Stability and Stabilization Methods", Second Edition, John Wiley \& Sons, Inc., New York.

[2] Al-Ashaal, A. A., Abdel-Motaleb, A.A., and Haggag, H. A., (1998), "Stabilizing Embankment Made of and Founded Over Weak Soil Using Piles: A Case History", Soil Mechanics and Foundations, Journal of the Egyptian Geotechnical Society, Vol.9.

[3] Al-Mamlouk, H., (2000b), "Technical Report about the Stabilizing System used in Stabilizing the Left Side Embankment of Al-Salam Canal, Second Stage, from $5.250 \mathrm{~km}$ to 10.000 km".

[4] Arai, K., and Tagyo, K., (1985), "Determination of Non Circular Slip Surface Giving the Min.FOS in Slope Stability", Japanese Society of Soil Mechanics and Foundation Engineering ,Soils and Foundations, Vol. 25, No. 1, pp.43- 51.

[5] Bhavikatti, S. S., (2005), "Finite Element Analysis", New Age International, New Delhi, India.

[6] Bishop, A. W. (1966), "The Strength of Soils as Engineering Materials", Sixth Rankine Lecture, Geotechnique, Vol. 16, No. 2, pp.89-130.

[7] Chen, W.F., and Liu, X.L., (1990), "Limit Analysis in Soil Mechanics", Elsevier Science Publisher.

[8] Chen, Z., (1999), "The Limit Analysis for Slopes: Theory, Methods and Applications", Proceedings, International Symposium on Slope Stability Engineering. IS-SHIKOKOU'99, Balkema.

[9] Cheng, Y.M., Lansivaara, T. and Wei, W.B. (2007a), "Two-Dimensional Slope Stability Analysis by Limit Equilibrium and Strength Reduction Methods", Computers and Geotechnics, Vol. 34, pp.137-150.

[10] Cheng, Y.M., and Lau, C.K., (2008), "Slope stability and stabilization (new methods and insight)", Routledge, Taylor \& Francis Group.

[11] Chowdhury, R., Flentje, P., and Bhattacharya, G., (2010), "Geotechnical Slope Analysis", Taylor \& Francis Group, London, UK.

[12] Duncan, J. M., and Wright, S. G. (1980), "The Accuracy of Equilibrium Methods of Slope Stability Analysis", Vol. 16, No. 1-2, pp.5-17.

[13] Duncan, J. M., and Wright, S. G., (2005), "Soil Strength and Slope Stability", John Wiley \& Sons, Inc., New York.

[14] Egyptian Code of Practice for Soil Mechanics, Design and Construction of Foundations, (2001), Part No. 8, Stability of Slopes.

[15] Hamza Associates, (1998), "Technical Report about Supporting and Strengthening of AlSalam Canal Left Embankment, Vibration Monitoring During Pile Driving".

[16] Salem, T. N., (1998), "Technical Report about the Static Cone Results for the Project of Strengthening the Lift Side Embankment of Al-Salam Canal", Roshdy Company for General Contracting and Trading.

[17] Salem, T. N., Haggag, H., (1998), "The Effect of the Driving Process on the Pore Water Pressure, the Left Side Embankment of Al-Salam Canal", Roshdy Company for General Contracting and Trading.

[18] Rashad, R. H.,(2012), "Analysis of Slope Stabilizing Piles", M. Sc. Thesis, Structural Eng. Dept., Zagazig Universit. 